\title{
Critical Parameters of Superconducting Materials and Structures
}

\author{
M.J. Fluss \\ R.H. Howell \\ P.A.Sterne \\ J.W. Dykes \\ W.D. Mosley
}

A. Chaiken

K. Ralls

H. Radousky

This is an informal report intended primarily for internal or limited external distribution. The opinions and conclusions stated are those of the author and may or may not be those of the Laboratory.

Work performed under the auspices of the U.S. Department of Energy by the Lawrence Livermore National Laboratory under Contract W-7405-Eng-48.

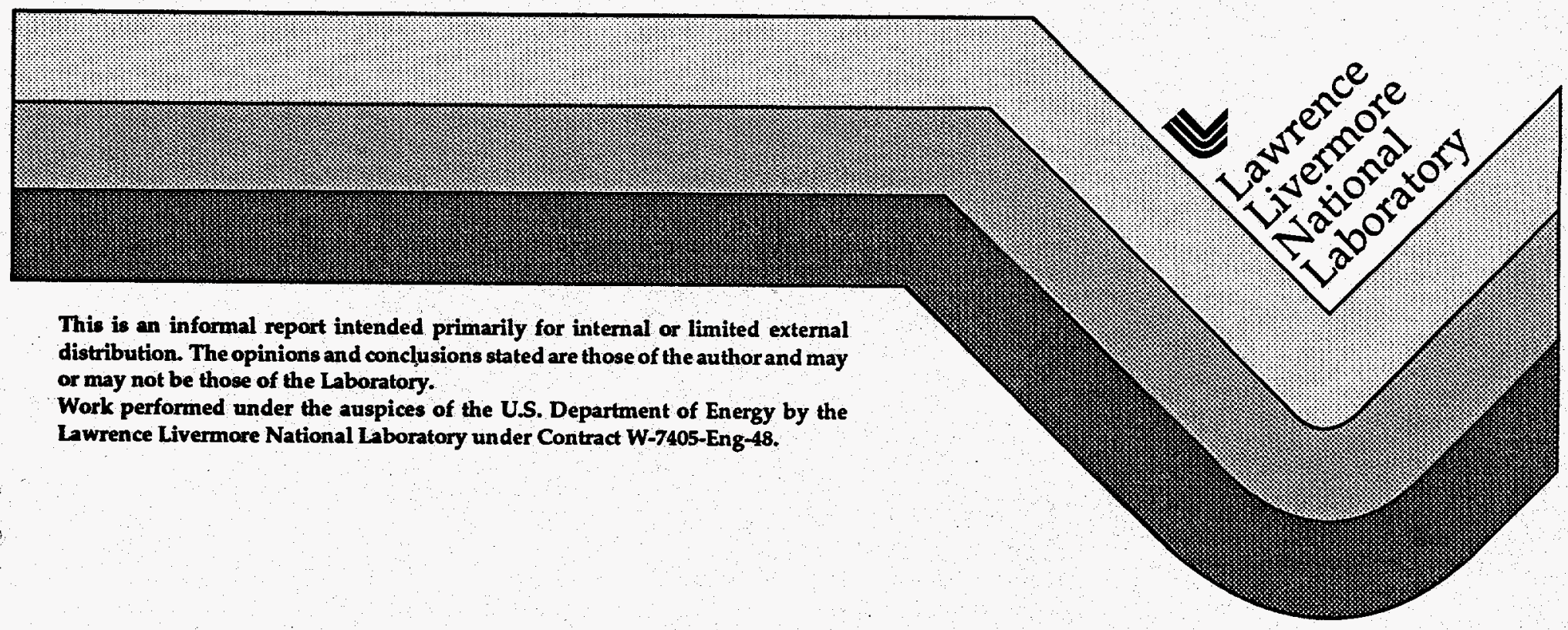




\section{DISCLAIMER}

This document was prepared as an account of work sponsored by an agency of the United States Government. Neither the United States Government nor the University of California nor any of their employees, makes any warranty, express or implied, or assumes any legal liability or responsibility for the accuracy, completeness, or usefulness of any information, apparatus, product, or process disclosed, or represents that its use would not infringe privately owned rights. Reference herein to any specific commercial product, process, or service by trade name, trademark, manufacturer, or otherwise, does not necessarily constitute or imply its endorsement, recommendation, or favoring by the United States Government or the University of California. The views and opinions of authors expressed herein do not necessarily state or reflect those of the United States Government or the University of California, and shall not be used for advertising or product endorsement purposes.

This report has been reproduced directly from the best available copy.

Available to DOE and DOE contractors from the Office of Scientific and Technical Information P.O. Box 62, Oak Ridge, TN 37831

Prices available from (615) 576-8401, FTS 626-8401

Available to the public from the National Technical Information Service

U.S. Department of Commerce

5285 Port Royal Rd.

Springfield, VA 22161 


\section{DISCLAIMER}

Portions of this document may be illegible in electronic image products. Images are produced from the best available original document. 


\title{
Critical Parameters of Superconducting Materials and Structures
}

\author{
M. J. Fluss, R. H. Howell, P. A. Sterne, J. W. Dykes, W. D. Mosley, \\ A. Chaiken, K. Ralls, and H. Radousky
}

\begin{abstract}
We report here the completion of a one year project to investigate the synthesis, electronic structure, defect structure, and physical transport properties of high temperature superconducting oxide materials. During the course of this project we produced some of the finest samples of single crystal detwinned $\mathrm{YBa}_{2} \mathrm{Cu} 3 \mathrm{O} 7$, and stoichiometrically perfect $(\mathrm{Ba}, \mathrm{K}) \mathrm{BiO} 3$. We deduced the Fermi surface of $\mathrm{YBa}_{2} \mathrm{Cu}_{3} \mathrm{O}_{7},(\mathrm{La}, \mathrm{Sr})_{2} \mathrm{CuO}_{4}$, and $(\mathrm{Ba}, \mathrm{K}) \mathrm{BiO}_{3}$ through the recording of the electron momentum density in these materials as measured by positron annihilation spectroscopy and angle resolved photoemission. We also performed extensive studies on $\mathrm{Pr}$ substituted $(\mathrm{Y}, \mathrm{Pr}) \mathrm{Ba}_{2} \mathrm{Cu}_{3} \mathrm{O}_{7}$ so as to further understand the origin of the electron pairing leading to superconductivity.
\end{abstract}

\section{INTRODUCTION}

As practical applications of high temperature superconducting materials grow nearer there remain significant gaps in our understanding of the superconducting phenomenon. We have investigated a variety of electronic and molecular structure issues as to how they relate to the basic physical phenomena/properties in several oxide superconducting systems. The research was enhanced with collaborators in industry and the UC system.

The electronic structure of superconducting materials has been a topic of fundamental importance in understanding the superconducting mechanism ever since the discovery of the high temperature superconducting phenomena. At LLNL we have performed a series of unique benchmark experiments to determine the details of the Fermi surface in $\mathrm{YBa}_{2} \mathrm{Cu}_{3} \mathrm{O}_{7-\mathrm{x}}$ inaccessible by other techniques by using angular correlation of the annihilation radiation of electron-positron pairs (ACAR) as well as the more well known synchrotron based angle resolved photo emission spectroscopy (ARPES). The ACAR data for $\mathrm{YBa}_{2} \mathrm{Cu}_{3} \mathrm{O}_{7-\mathrm{x}}$ first established the conductivity of the copper oxygen chains and remains the most convincing experimental evidence of this feature which confirms predictions of detailed band structure calculations at LLNL and NRL. Not all the high temperature superconductors have this interesting chain structure, but most have a common $\mathrm{Cu}-\mathrm{O}$ plane from which the dominant high temperature superconductivity is believed to arise. As a result of this reasoning we set out to observe the evolution of the electronic structure of the first high temperature superconductor $(\mathrm{La}, \mathrm{Sr})_{2} \mathrm{CuO}_{4}$ which has only one $\mathrm{Cu}-\mathrm{O}$ plane in the unit cell so as to compare to models treating the basic issues of electron correlation in superconducting oxides.

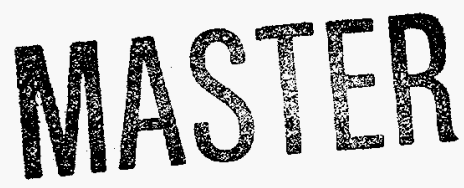




\section{FERMI SURFACE vs. DOPING}

We have measured the shape and location of the Fermi surface in $(\mathrm{La}, \mathrm{Sr})_{2} \mathrm{CuO}_{4}$ using the positron ACAR for $\mathrm{Sr}$ dopings of $0.1,0.13$, and 0.2 and observed the evolution of the Fermi surface as the hole doping in the system is increased. These measurements were analyzed in coordination with detailed calculations of the ACAR measurement in the (La,Sr) ${ }_{2} \mathrm{CuO}_{4}$ system using the Linear Muffin Tin Orbital method. Samples were single crystals of $(\mathrm{La}, \mathrm{Sr}){ }_{2} \mathrm{CuO}_{4}$ grown by the "spinning crucible" method obtained from collaborators at the University of Tokyo. The details of the changes in the Fermi surfaces observed as a function of $\mathrm{Sr}$ doping are not reproduced by our theory leading us to the conclusion, after detailed analysis for systematic errors and model limitations, that the Fermi surface is distorted or smeared as doping is increased.

We have explored the possible causes of the Fermi surface smearing in this system. Some such as $\mathrm{Sr}$ disorder, or effects due to changes in the positron sampling function ( the overlap of the positron wave function with the occupied electron states) have been found to be highly unlikely. The likelihood that the observed Fermi surface smearing effects are due to electron correlations is growing and is the subject of many new research initiatives.

\section{STOICHIOMETRIC DEFECTS}

$(\mathrm{Ba}, \mathrm{K}) \mathrm{BiO}_{3}$ is a copper-free superconducting oxide with a transition temperature above $31 \mathrm{~K}$. Due to the lack of magnetic ions in the structure and its high onset temperature, it is to believed hold much promise in technological applications. In collaboration with Dave Mosley, Peter Klavins (both graduate student employees in C\&MS), and Robert Shelton at the UC Davis physics department, we have investigated the phase diagrams and the influence of cation defects and oxygen stoichiometry on the magnetic and transport properties of high-quality electrodeposited crystals of the material. By combining positron annihilation measurements and calculations, we have determined that unlike the melt textured material, electrodeposited $(\mathrm{Ba}, \mathrm{K}) \mathrm{BiO}_{3}$ is free of cation defects. More importantly, it was also determined that these samples lack full oxygen stoichiometry. When the samples were annealed in an oxygen rich atmosphere, oxygen uptake was observed by an amount which corresponded well to theoretical calculations. Oxygen uptake has been found to lower the normal state resistivity and to improve the metallic dependence of resistance versus temperature measurements. Oxygenating $(\mathrm{Ba}, \mathrm{K}) \mathrm{BiO}_{3}$ also effects the superconducting properties by increasing the onset temperature and sharpening the transition.

We have also determined the Fermi surface in well oxygenated, large single crystals of $(\mathrm{Ba}, \mathrm{K}) \mathrm{BiO}_{3}$. The shape of the Fermi surface agrees well with calculations predicting surface regions capable of "nesting behavior" which is usually associated with BCS superconductivity.

\section{POISONING of HIGH TEMPERATURE SUPERCONDUCTIVITY}

Pr is the only rare earth that fails to give a superconducting system in the 123 oxide structure. Extensive doping and transport studies were performed on ceramic and single crystal samples of the $(Y, P r) \mathrm{Ba}_{2} \mathrm{Cu}_{3} \mathrm{O}_{7}$ system have resulted in a good 
understanding of the relative role of $\mathrm{Pr}$ in changing the charge distribution and the spin distribution in $\mathrm{YBa}_{2} \mathrm{Cu}_{3} \mathrm{O} 7-\mathrm{x}$.

\section{STRUCTURE-PROPERTY RELATIONSHIPS in HIGH TC PLANAR JUNCTIONS}

We have collaborated with Varian Research Corporation to study the physical properties of transport in unique superconductor-insulator-superconductor junctions. Films of superconducting $\mathrm{Bi}_{2} \mathrm{Sr}_{2} \mathrm{CaCu}_{2} \mathrm{O}_{8}$ and related compounds are being fabricated by atomic layer by atomic layer using molecular beam epitaxy at Varian Research Corporation. This fabrication technique has resulted in new compounds and phases that would not form in bulk processing techniques. Metastable structures such as superlattices of successive $\mathrm{Bi}(2212)$, and $\mathrm{Bi}(2201)$ unit cells, unit cells containing only one layer of bismuth oxide rather than the usual two, and unit cells containing an arbitrary number of copper-oxygen layers have all been fabricated. Two layers of superconducting $\mathrm{Bi}(2212)$ separated by an insulating layer containing seven copperoxygen and calcium layers doped with dysprosium have been deposited. After depositing electrode material these three component films are patterned into complete tunneling devices to form Superconductor-Insulator-Superconductor Josephson Junctions.

These devices form good Josephson junctions at low temperature and have sharp Shapiro steps under microwave illumination. These are the only tunnel junctions that depend on transport along the $c$ axis perpendicular to the copper-oxygen plane and they have unique properties when compared with junctions formed by in-plane transport. They are the first high temperature Josephson junctions to show hysteresis in the current-voltage characteristics and they can be fabricated so that the product of critical current and normal state junction resistance is constant while the critical current varies by decades. Details of the temperature dependence of the current flow through the insulating layer have identified a hopping mechanism for the charge transport in some insulating phases. Other SIS combinations lack these characteristics as the properties of the Josephson junctions are correspondingly modified.

This collaboration has continued past the end of the LDRD project through a CRADA with Varian and funding from the Technology Transfer Initiative. This work has resulted in a better scientific understanding of both the superconducting mechanism and the film deposition process. 


\section{BIBLIOGRAPHY}

W. D. Mosley, J. W. Dykes, R. N. Shelton, P.A. Sterne, R. H. Howell, "Direct Observation of the Fermi Surface in $\mathrm{Ba}_{1-x} \mathrm{~K}_{x} \mathrm{BiO}_{3}$," UCRL JC-115823, Phys. Rev. Lett. 731271 (1994).

W. D. Mosley, M. D. Lan, P.A. Sterne, R. H. Howell, R. N. Shelton "Correlation of Magnetic Properties to Oxygen and Potassium Stoichiometry in Single Crystal Ba 1x $\mathrm{K}_{\mathrm{x}} \mathrm{BiO}^{\prime \prime}$ Journal of Superconductivity 7, 299 (1994).

R. H. Howell , P.A. Sterne, M. J. Fluss , J. H. Kaiser , K. Kitazawa, And H. Kojima "Influence Of Doping On The Electronic Structure Of ( $\mathrm{La}, \mathrm{Sr})_{2} \mathrm{CuO}_{4}$ " Journal of Superconductivity 7, 169 (1994).

R. H. Howell, P. A. Sterne, M. J. Fluss, J. H. Kaiser, K. Kitazawa and H. Kojima, "Evolution of the Electronic Structure of $\mathrm{La}_{2-x} \mathrm{Sr}_{x} \mathrm{CuO}_{4}$ with Doping Determined by Positron Annihilation Spectroscopy," UCRL-JC-115098, Phys. Rev. B 19 , 13217 (1994).

R. H. Howell, P. A. Sterne, F. Solal, M. J. Fluss, J. Tobin, J. O'Brien, H. B. Radousky, H. Haghighi, J. H. Kaiser, S. Rayner, R. N. West, J. Z. Liu, R. Shelton, C. G. Olsen, C. Gu, K. Kitazawa and H. Kojima "Electronic Structure in High Temperature Superconducting Oxides," UCRL-JC-108266 Positron Annihilation, Zs Kajcsos and Cs. Szeles, Trans Tech Publications, Aedermannsdorf, Switzerland, p265, (1992)

P.A. Sterne, R. H. Howell, M. J. Fluss, J. H. Kaiser, K. Kitazawa, H. Kojima, "Positron Annihilation Study of Doping in La 2-x $\mathrm{Sr}_{x} \mathrm{CuO} 4 ", \mathrm{UCRL} J C-112045$, Jour. Phys and Chem of Solids $\underline{54}, 1231$ (1993)

W. D. Mosley, J. W. Dykes, P. Klavins, R. N. Shelton, P.A. Sterne, R. H. Howell, "Correlation of Superconducting Transition to Oxygen Stoichiometry in Single Crystal

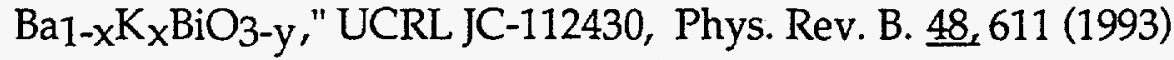

R. H. Howell, P. A. Sterne, F. Solal, M. J. Fluss, J. Tobin, J. O'Brien, H. B. Radousky, H. Haghighi, J. H. Kaiser, S. Rayner, R. N. West, J. Z. Liu, R. Shelton, C. G. Olsen, C. Gu, K. Kitazawa and H. Kojima "Electronic Structure in High Temperature Superconducting Oxides," UCRL-JC-108266 Positron Annihilation, Zs Kajcsos and Cs. Szeles, Trans Tech Publications, Aedermannsdorf, Switzerland, p265, (1992)

H. Haghighi, J. H. Kaiser, S. Rayner, R. N. West, J. Z. Liu, R. Shelton, R. H. Howell, P. A. Sterne, F. Solal, M. J. Fluss, "The Electron-Positron Momentum Density and Fermi Surface in YBa2Cu3O7-d," UCRL-JC-108674, Positron Annihilation, Zs Kajcsos and Cs. Szeles, Trans Tech Publications, Aedermannsdorf, Switzerland, p249, (1992) 
K. S. Ralls, I. Bosovic, G. F. Virshup, M. E. Klausmeier-Brown, J. N. Eckstein, "Two state hopping and Its Impact on Superconducting Transport in Tri-layer Bi-Sr-Ca-Cu-O Devices with Heavily Doped Barriers", submitted to Phys. Rev. B

M. E. Klausmeier-Brown, G. F. Virshup, I. Bosovic, J. N. Eckstein, K. S. Ralls, "Engineering of Ultra-thin Barriers in High Tc Tri-layer Josephson Junctions", Appl. Phys. Lett. 60, 2806 (1992)

J. N. Eckstein, I. Bosovic, M. E. Klausmeier-Brown, G. F. Virshup, K. S. Ralls, "Atomically layered growth and properties of high temperature superconducting single-crystal films and superlattices" Thin Solid Films 216, 81992

P. A. Sterne. H. Kaiser, J. C. O'Brien and R. H. Howell, "Positron Lifetimes in Solids from First Principles Calculations", Positron Annihilation, Zs Kajcsos and Cs. Szeles, Trans Tech Publications, Aedermannsdorf, Switzerland, p469, (1992)

H. Haghighi, J. H. Kaiser, S. Rayner, R. N. West, J. Z. Liu, R. Shelton, R. H. Howell, P. A. Sterne, F. Solal, M. J. Fluss, "Direct Experimental Evidence of the Fermi Surface in YBa2Cu3O7-d," UCRL-JL-105361, High Temperature Superconductivity, Physical properties, Microscopic Theory and Mechanisms, ed J. Ashkenazi, S. E. Barnes, F. Zuo, G. C. Vezzoli and B. M. Klein (Plenum Publishing, New York), p183 (1992).

J. G. Tobin, C. G. Olson, C. Gu, D. W. Lynch, J. Z. Liu, F. R. Solal, M. J. Fluss, R. H. Howell, J. C. O'Brien, H. B. Radousky, P. A. Sterne, "The Valence Bands and Fermiology of Untwinned Single Crystal YBa2 Cu3 O6.9," Phys. Rev. B 45 , 5563 (1992).

R. H. Howell, P.A. Sterne, F. R. Solal, M. J. Fluss, J. H. Kaiser, R. N. West, H. Kojima, K. Kitazawa, "Fermi Surface Measurements in $\mathrm{YBa}_{2} \mathrm{Cu}_{3} \mathrm{O} 7-\mathrm{d}$ and $\mathrm{La}_{2-\mathrm{x}} \mathrm{Sr}_{\mathrm{X}} \mathrm{CuO} 4$ " UCRL JC 107009, Physica C 185, 735 (1991).

\section{INVITED TALKS}

J. N. Eckstein, I. Bosovic, M. E. Klausmeier-Brown, G. F. Virshup, K. S. Ralls, "Control of Composition and Microstructure at the Atomic Level by Molecular Beam Epitaxy", MRS Boston, Nov., 1992

P.A. Sterne, R. H. Howell, M. J. Fluss, J. H. Kaiser, K. Kitazawa, H. Kojima, "Positron Annihilation Study of Doping in $\mathrm{La}_{2-x} \mathrm{Sr}_{x} \mathrm{CuO}_{4}$ " Conference on Spectroscopies in Novel Superconductors, Santa Fe New Mexico March 1992

R. H. Howell, P.A. Sterne, M. J. Fluss, J. H. Kaiser, K. Kitazawa, H. Kojima, "Electronic Structure of ( $\mathrm{La}, \mathrm{Sr})_{2} \mathrm{CuO}_{4}$ by Positron Annihilation Spectroscopy," International Superconducting Symposium, ISS'92, November 16-19, 1992, Kobe Japan 
R. H. Howell, P.A. Sterne, M. J. Fluss, J. H. Kaiser, K. Kitazawa, H. Kojima, "Influence Of Doping On The Electronic Structure Of $(\mathrm{La}, \mathrm{Sr})_{2} \mathrm{CuO}_{4}$," Physics and Chemistry of Molecular and Oxide Superconductors Eugene, Or, July 1993

W. D. Mosley, J. W. Dykes, P. Klavins, R. N. Shelton, P.A. Sterne, R. H. Howell, Physics and Chemistry of Molecular and Oxide Superconductors Eugene, Or, July 1993 